\title{
Quadro institucional para o desenvolvimento sustentável: o papel dos países em desenvolvimento com base na análise crítica do discurso da Rio+20
}

\author{
Institutional framework for sustainable development: the role of developing countries based \\ on a critical discourse analysis of Rio+20
}

\author{
Paulo Thiago Nunes Bezerra de Melo ${ }^{1}$ \\ Helena Kuerten de Salles ${ }^{2}$ \\ Hans Michael van Bellen ${ }^{3}$
}

\section{Resumo}

Na Rio+20, conferência da Organização das Nações Unidas (ONU) sobre o desenvolvimento sustentável, dois temas foram debatidos: economia verde e o quadro institucional para o desenvolvimento sustentável. Visando contribuir para a discussão deste segundo tema, investigou-se o papel dos países em desenvolvimento na dimensão institucional do desenvolvimento sustentável segundo percepção da ONU. Para isto, com base na análise crítica do discurso, foi analisado o relatório que examina os temas desta conferência, tendo sido constatados, pelo menos, dois papéis atribuídos aos países em desenvolvimento: recebedores e beneficiários de investimentos de fundos internacionais para o desenvolvimento sustentável e produtores e consumidores insustentáveis.

Palavras-chave: Desenvolvimento sustentável. Países em desenvolvimento. Análise crítica do discurso. Rio+20.

\begin{abstract}
At the Rio+20 conference of the United Nations (UN) on sustainable development, two issues were discussed: the green economy and the institutional framework for sustainable development. To contribute to the discussion of the latter issue, we investigated the role of developing countries for the institutional dimension of sustainable development in the perception of the UN. To this end, guided by critical discourse analysis, we analyzed the report which examines the themes of this conference and found at least two roles assigned to developing countries: recipients and beneficiaries of international investment funds for sustainable development and unsustainable producers and consumers.
\end{abstract}

Keywords: Sustainable development. Developing countries. Critical discourse analysis. Rio+20.

\footnotetext{
Texto submetido em 30 de julho de 2012 e aceito para publicação em 13 de agosto de 2012.

${ }^{1}$ Doutorando em Administração/UFSC. Endereço: CPGA, Centro Sócio-Econômico, Campus Universitário, Trindade, CEP 88040-900, Florianópolis - SC, Brasil. E-mail: pthiagoadm@hotmail.com

2 Doutoranda em Administração/UFSC. Endereço: CPGA, Centro Sócio-Econômico, Campus Universitário, Trindade, CEP 88040-900, Florianópolis - SC, Brasil. E-mail: helenasalles@yahoo.com.br

3 Doutor em Engenharia de Produção/UFSC. Endereço: CPGA, Centro Sócio-Econômico, Campus Universitário, Trindade, CEP 88040-900, Florianópolis - SC, Brasil. E-mail: hansmichael@cse.ufsc.br
} 


\section{Introdução}

Neste estudo, busca-se discutir o papel dos países em desenvolvimento na avaliação das Nações Unidas sobre o quadro institucional para o desenvolvimento sustentável, de acordo com o relatório da assembleia geral sobre os objetivos e temas da Conferência das Nações Unidas sobre Desenvolvimento Sustentável em 2012, conhecida por Rio+20. Esta discussão é guiada pela análise crítica do discurso sobre o documento.

O desenvolvimento das nações, encarado como um movimento de mudanças em direção ao progresso, ou seja, em direção a uma situação cada vez mais favorável, tem sido um tema exaustivamente discutido a partir do século XX. Contudo, no século XVI, os países europeus já realizavam mudanças políticas e econômicas que construiriam um caminho sem volta para muitos povos no futuro. Os países que naquele momento procuravam expandir seus mercados encontraram solução em terras desconhecidas que viriam a ser colônias e, mais tarde, países fadados ao subdesenvolvimento. Hoje, ao analisar as experiências do passado, é possível conhecer meios que permitam a países de desenvolvimento tardio se aproximarem da situação dos que largaram primeiro nesta corrida, bem como perceber que alguns destes pioneiros foram sujeitos de um movimento de retração. Mas ganhar postos nesta corrida é certamente uma tarefa que requer esforços maiores do que a de perder postos.

Nas últimas décadas, a corrida em direção aos postos mais altos tornou-se um jogo repleto de acordos que, apesar de multilaterais, favorecem geralmente apenas um lado, colocando o outro em uma situação de submissão perante o poder hegemônico do bloco de países mais desenvolvidos. Entre muitos destes acordos, estão aqueles que tratam da sustentabilidade do desenvolvimento.

Desde que a sustentabilidade do desenvolvimento tornou-se um tema de destaque em discussões de diversos setores da sociedade, vários eventos e organizações tomaram a iniciativa de provocar a mudança no comportamento dos cidadãos e, particularmente, dos lideres de governos nacionais. Nas últimas décadas, as conferências realizadas pelas Nações Unidas sobre desenvolvimento sustentável tornaram-se eventos que têm ancorado as discussões sobre o tema ao redor do mundo. Em 2012, mais uma conferência concretiza-se marcando 20 anos da primeira conferência, na qual se discutiu o tema em 1992 no Rio de Janeiro.

Ao longo destes 20 anos, algumas questões específicas entraram e saíram da pauta de discussões das conferências, em virtude do contexto do desenvolvimento econômico e social em cada momento. Atualmente, dois são os temas de interesse das Nações Unidas discutidos na conferência Rio+20: a economia verde e o quadro institucional para o desenvolvimento sustentável. Visando contribuir para a discussão deste segundo tema é que este estudo se realiza. As instituições, sejam como uma forma organizacional ou como a solidificação de um comportamento social, estão, cada vez mais, se fazendo presentes nas discussões sobre desenvolvimento sustentável, tanto no campo teórico quanto nas aplicações práticas de avaliação da sustentabilidade em nível local, nacional ou regional. Segundo as Nações Unidas (UNITED NATIONS, 2010), o quadro institucional tem crescido - atualmente há mais de quinhentos acordos ambientais multilaterais.

Desta forma, neste estudo busca-se responder a seguinte pergunta: qual o papel dos países em desenvolvimento no relatório das Nações Unidas para a dimensão institucional do desenvolvimento sustentável? Para tanto, recorre-se à Análise Crítica do Discurso (ACD) e, por meio da desconstrução do discurso da Organização das Nações Unidas (ONU), busca-se verificar na concepção desta qual o papel dos países em desenvolvimento na dimensão institucional do desenvolvimento sustentável.

A seguir será apresentado um breve referencial teórico sobre as abordagens de desenvolvimento, os países em desenvolvimento no contexto mundial e o desenvolvimento sustentável. Em seguida, será apresentado o percurso metodológico tomado para responder as questões anteriores. Os resultados serão apresentados com a análise das considerações sobre a hegemonia no texto das Nações Unidas sobre o quadro institucional para o desenvolvimento sustentável. Na seção seguinte, caberão algumas considerações finais e sugestões de futuras pesquisas. 


\section{Desenvolvimento, Meio Ambiente e Ordem Internacional}

O progresso, conforme analisado por Furtado (1980), está imbricado com transformações sociais em decorrência das adaptações, especificamente na mudança forçada dos valores simbólicos que regem as relações nas novas regras do mercado. Com relação à distinção entre desenvolvimento e subdesenvolvimento, Furtado (1980) afirma que três dimensões devem ser observadas: a eficácia dos sistemas de produção, as necessidades elementares da população e o alcance de objetivos dos grupos dominantes na utilização de recursos escassos.

Sen (2000) apresenta uma ideia da dimensão humana do desenvolvimento em complementaridade à dimensão econômica. É ressaltada a importância da liberdade individual substantiva como um fator de desenvolvimento. Desta forma, o desenvolvimento é visto como uma função da liberdade de escolha dos indivíduos nas diversas formas que a vida social proporciona. No entanto, também é destacada a situação urgente dos indivíduos que vivem em condições nas quais sua liberdade é tolhida, cabendo aos indivíduos com melhores condições escolherem entre agir de alguma maneira responsável ou não. Portanto, a grande contribuição de Sen (2000) para a teoria do desenvolvimento é o foco nos indivíduos, uma vez que o tema do desenvolvimento é constantemente tratado pelo viés econômico com destaque para os índices de acumulação material. Souza (1999) apresenta um aprofundamento sobre o conceito de desenvolvimento estabelecendo diferenças com o conceito de crescimento. Uma contribuição adicional de Souza (1999) é a compreensão da estrutura de uma economia subdesenvolvida. Neste ponto, o autor ressalta o processo de substituição de importações que é financiado pelas exportações dos excedentes da produção agrícola. Desse modo, realizase, uma transição de uma economia predominantemente agrária e rural para uma economia industrializada e urbana ao longo do tempo.

Chang (2002) afirma que os países desenvolvidos tentam impor aos países em desenvolvimento uma "receita" para o desenvolvimento diferente das utilizadas por eles, o que coloca os países em desenvolvimento em posição de dependência aos desenvolvidos. Mais do que isso, Chang (2002) também afirma que a história verdadeira sobre como os países atualmente desenvolvidos conseguiram se desenvolver é constantemente omitida nos discursos oficiais, na tentativa de fazer valer atualmente as regras de mercado que privilegiam apenas a eles em vez de ajudar os outros países a se desenvolverem também. De acordo com Chang (2002), parece haver um movimento semelhante aos países desenvolvidos do protecionismo das indústrias nascentes nacionais em um primeiro momento para o liberalismo comercial, mesmo que parcial, em um momento posterior.

Ao tratar da questão das riquezas das nações, especificamente do desenvolvimento dos países atrasados e da distribuição desigual das riquezas entre as nações, Fiori (1999) promove um debate de uma perspectiva histórica acerca dos caminhos e da viabilidade de um desenvolvimento econômico nacional. O autor discute o processo da globalização levando-se em conta questões específicas da internacionalização das economias e, sobretudo, do mercado financeiro, e ressalta que se trata de uma ideia capitalista neoliberal que, ao mesmo tempo que permite a integração econômica dos países, aprofunda as desigualdades sociais.

Fiori (1997) também discute sobre a competição estatal e hegemonia, com o foco central em tentar explicar as razões de existir uma nação hegemônica para guiar o desenvolvimento dos demais países. Para Alves (2010), a noção gramsciana de hegemonia mostra a centralidade das superestruturas na análise das sociedades avançadas. Com base na revisão do conceito de hegemonia, Garcia (2010) destaca que as organizações internacionais são um mecanismo de universalização de normas da hegemonia mundial, pois incorporam as regras que facilitam a expansão de ordens mundiais hegemônicas e legitimam ideologicamente as normas desta ordem. Para Garcia (2010), o termo "hegemonia" pode ser usado tanto para indicar uma ordem mundial estável e "benévola" quanto uma ordem de dominação e imposição construída por meio de instituições que organizam o consenso e a coerção. Garcia (2010) afirma que a ordem hegemônica estabelecida pelas instituições pode ser vista em uma perspectiva gramsciana de universalização de regras, normas e valores particulares. 
Furtado (1994) afirma que a divisão internacional do trabalho impõe limitações ao mundo periférico. A teoria do subdesenvolvimento constitui a tomada de consciência dessas limitações. Para Furtado (1994), as economias centrais geram tecnologia baseadas nos problemas que enfrentam, e estas tecnologias são requeridas nas demais economias. Os aspectos econômicos do subdesenvolvimento são acentuados por Cardoso e Faletto (1975) no conceito de dependência como instrumento teórico.

A caracterização da forma de relação entre os centros imperialistas e os países dependentes é o ponto básico à compreensão do processo histórico na América Latina, segundo Cardoso (1993). Os processos de dependência e de desenvolvimento capitalista existem simultaneamente. As empresas estatais, as corporações multinacionais e as empresas locais associadas a ambos passam a ser os beneficiários desse "desenvolvimento dependente", constituindo o "tripé do desenvolvimento dependente-associado" (CARDOSO, 1993, p. 107). Cardoso de Mello (1997) afirma que, sob a égide do livre jogo das forças de mercado, o desenvolvimento desigual da economia mundial tende a se reproduzir e a se aprofundar nos termos da relação centro-periferia. Segundo Cardoso de Mello (1997), três tipos de controle definem o centro: controle exercido sobre o processo de inovação tecnológica, o controle da moeda e da finança internacionalizada e controle do poder político e militar. Já a periferia subdesenvolvida é caracterizada por três elementos: a dependência do sistema produtivo, fragilidade monetária e financeira externa, e a subordinação político-militar.

Almeida (2009) faz uma revisão e comparação das ideias de Celso Furtado e Fernando Henrique Cardoso no período entre 1950 e 1990. Para Furtado, a internacionalização dos mercados comandada pelas empresas transnacionais enfraquecia o poder de intervenção do Estado na regulação da atividade econômica. Para Cardoso, não restava outra opção para o Brasil a não ser a inserção de forma subalterna na economia mundial, sob as regras impostas pelas empresas transnacionais. Ao distinguir as ideias de Cardoso e Furtado, Almeida (2009) afirma que eles apresentam pontos de vista diferentes quanto à associação de capital periférico com o capitalismo central e à perspectiva de desenvolvimento diante da dependência. Cardoso preconizou o tripé formado pela parceria entre o capital privado nacional, o capital internacional e o setor estatal como sustentáculo do desenvolvimento dependente-associado. Furtado ressalta a necessidade de controle dos capitais estrangeiros em direção aos interesses do Estado. Tanto Cardoso quanto Furtado afirmam que o capital estrangeiro é indispensável como instrumento de cooperação ao desenvolvimento.

Arrighi (1997) chama atenção para os Estados que parecem estar em uma situação estacionária, ao longo do tempo, entre o núcleo orgânico e a periferia. As atividades do núcleo orgânico e da periferia estão presentes, em maior ou menor grau, em todos os Estados. Por um lado, os países do núcleo orgânico apresentam predominância de atividade de núcleo orgânico, sendo o locus de acumulação e poder. Por outro lado, os países da periferia apresentam predominância de atividade da periferia, sendo o locus da exploração e da impotência. Uma combinação mais ou menos igual das atividades do núcleo orgânico e periféricas caracteriza os países da semiperiferia, que não têm poder para ascender ao núcleo orgânico e resistem em se tornar periféricos.

Segundo Conceição (2002), para compreender as trajetórias de crescimento econômico, as instituições são fundamentais e estratégicas. Devido à diversidade de abordagens, nem sempre convergentes, as instituições são definidas de maneira heterogênea, como normas ou padrão de comportamento, formas institucionais, padrão de organização ou como direito de propriedade. Os aspectos históricos da formação econômica nacional devem ser levados em conta nas análises dos padrões nacionais de desenvolvimento, em virtude de este ter se dado em uma base institucional. Arend e Cario (2010) discutem como as instituições originam-se, evoluem e afetam o desempenho econômico industrial de determinada região. Arend e Cario (2010) afirmam que o processo de desenvolvimento econômico é dependente de fatores institucionais e tecnológicos, que, por sua vez, são dependentes de eventos passados. Trata-se, portanto, de processo cumulativo ou histórico. Assim, o processo de desenvolvimento econômico é dependente da trajetória passada.

Atualmente, quando o tema de desenvolvimento é tratado, é impossível dissociar tal discussão das preocupações com a sustentabilidade do meio ambiente e dos sistemas econômico e social. O risco de existência das condições de vida no planeta está associado ao crescimento da população e das atividades 
econômicas. O planeta tem sofrido degradação tanto por parte dos países mais ricos, devido à industrialização, quanto dos países mais pobres, devido ao crescimento populacional excessivo (KENNEDY, 1993).

Em uma perspectiva do determinismo ambiental, Diamond (2005) afirma que o aumento do impacto humano total decorrente da melhora do padrão de vida da população do Terceiro Mundo é o maior problema para o meio ambiente. Ele também destaca o crescimento populacional como o problema que afeta todos os outros possíveis problemas no meio ambiente, mesmo chamando atenção para a necessidade de resolução de todos estes devido às conexões entre eles.

Quando se refere ao ambientalismo, Viola (1996) afirma que a preocupação pública com problemas ambientais tem crescido desde meados da década de 1960, com origem na América do Norte. Segundo Leis (2004), foi no campo científico que os primeiros atores ambientalistas de transcendência mundial surgiram na segunda metade do século XX. Nos anos 60 e 70, a sociedade civil começou a se tornar ativa nas questões ambientalistas por meio de organizações não governamentais, e nos anos 80 , esta ação passou a ser globalizada por meio de redes em todo o planeta. Também foi nos anos 70 que os ambientalistas começaram a se mobilizar politicamente. Nos anos 90 , as teorias e práticas ambientalistas tornaram evidentes as implicações espirituais. Nesse sentido, o autor prescreve que "[...] é necessário desenvolver uma espiritualidade menos antropocêntrica, somando esforços na direção de uma re-sacralização da natureza" (LEIS, 2004, p. 125). Ao longo do tempo, o ambientalismo transformou-se em um movimento multissetorial.

O movimento ambientalista, na sua forma mais determinista, está engajado em ações de preservação da natureza, posicionando-se contra qualquer atividade econômica que vise à utilização de recursos naturais ou causem implicações nos ecossistemas. Contudo, o progresso econômico e social alinhado à conservação dos ecossistemas deu origem às discussões sobre o desenvolvimento sustentável. Os defensores do desenvolvimento sustentável diferenciam-se dos defensores da sustentabilidade pura pelo nível de aceitação das implicações das atividades econômicas. É sobre o viés do desenvolvimento sustentável que este estudo se posiciona.

Segundo Veiga (2007), em 1979, em um Simpósio das Nações Unidas, a expressão "desenvolvimento sustentável" foi empregada pela primeira vez. O desenvolvimento sustentável pode ser visto como "[...] uma nova maneira de a sociedade se relacionar com seu ambiente de forma a garantir a sua própria continuidade e a de seu meio externo" (VAN BELLEN, 2006, p. 22). Existe um enorme número de definições do conceito de desenvolvimento sustentável, originário de várias abordagens. Veiga (2007, p. 60) conceitua-o como uma situação em que "[...] o crescimento econômico respeite os limites da natureza em vez de destruir seus ecossistemas" e seja oferecida "[...] uma chance às gerações futuras de que também possam progredir". A primeira definição para desenvolvimento sustentável, dada pela Comissão de Brundtland, foi de desenvolvimento que satisfaz as necessidades presentes, sem comprometer a capacidade das gerações futuras de suprir suas próprias necessidades (UNITED NATIONS, 1987). Desde então, cada estudioso ou gestor que se apropria do tema têm articulado e promovido a sua própria definição, levando a que não se estabeleça uma definição clara, fixa e imutável. Esta ideia permanece dinâmica e em evolução, podendo ser adaptada para se ajustar a situações e contextos muito diferentes (KATES, PARRIS e LEISEROWITZ, 2005).

Leis (2004) faz uma crítica ao reconhecer que o mundo é cada vez mais uma realidade global, onde predominam o pensamento e a política realistas, que guiam o progresso por meio de hegemonias nacionais baseadas no poder. No âmbito da teoria política, o autor destaca que a emergência de um ambientalismo global e multissetorial requer uma política menos nacional, extensiva à humanidade e ao planeta.

Uma questão importante para o desenvolvimento sustentável é a avaliação da situação de um determinado contexto. Para verificar a sustentabilidade ou não do desenvolvimento e identificar ameaças, é preciso desenvolver indicadores como forma de operacionalização do conceito de desenvolvimento sustentável, considerando as dimensões ambiental, econômica e social (VAN BELLEN, 2010). Na dimensão ambiental, a principal preocupação são os impactos das atividades humanas sobre o meio ambiente. A dimensão econômica abrange alocação e distribuição eficientes dos recursos naturais dentro de uma escala apropriada. 
Na dimensão social, a preocupação principal está na condição humana e nos meios utilizados para aumentar a qualidade de vida.

Mais recentemente, o desenvolvimento sustentável na perspectiva da qualidade de vida tem chamado atenção. Bijl (2011) afirma que o desenvolvimento sustentável deve conferir estado central à qualidade de vida para as gerações presentes e futuras. A questão central no que se refere à sustentabilidade é se o bemestar pode ser mantido em longo prazo em um nível que vai permitir às gerações atuais e futuras oportunidade de desfrutar de uma boa qualidade de vida. Paralelamente, a prosperidade econômica e a sustentabilidade ecológica são vistas como parte ou condição para a qualidade de vida. Quando se trata de indicadores de qualidade de vida, um importante documento é o relatório "Report by the Commission on the Measurement of Economic Performance and Social Progress", publicado em 2009 por uma comissão liderada pelos vencedores de Prêmio Nobel, Joseph Stiglitz e Amartya Sen, e do economista francês JeanPaul Fitoussi, a pedido do presidente francês Sarkozy. No relatório argumentam convincentemente que os métodos tradicionais de medição do desenvolvimento social mediante indicadores econômicos deixam muito a desejar, tornando o momento propício para dedicar atenção a medir o bem-estar dos cidadãos em uma perspectiva de sustentabilidade (STIGLITZ, SEN e FITOUSSI, 2009). Com base neste relatório, a Organização para a Cooperação e Desenvolvimento Econômico (OECD) tem desenvolvido esforços para fornecer informações sobre a qualidade de vida dos cidadãos, partindo da ideia de que os recursos econômicos não são suficientes para capturar a qualidade de vida corretamente (ORGANIZAÇÃO PARA A COOPERAÇÃO E DESENVOLVIMENTO ECONÔMICO, 2009).

No que se refere a acordos internacionais sobre o desenvolvimento sustentável, Ribeiro (2010) discute a ordem ambiental internacional, que visa regular as relações humanas em caráter mundial envolvendo temas relacionados ao ambiente por meio de protocolos e acordos multilaterais entre países e blocos de países. Três reuniões foram particularmente importantes para a ordem ambiental internacional. Em 1972, na reunião de Estocolmo, foi criado o Programa das Nações Unidas para o Meio Ambiente (Pnuma) com o objetivo de comandar as discussões ambientais em escala mundial, e, também, foram discutidos os limites do crescimento econômico. Na Conferência das Nações Unidas para o Meio Ambiente e Desenvolvimento (Cnumad), no Rio de Janeiro, em 1992, foram criados documentos importantes como a Convenção sobre Diversidade Biológica, a Convenção-Quadro sobre Mudanças Climáticas e a Agenda XXI. E, na reunião de Joanesburgo, em 2002, foi feita uma avaliação da Cnumad. Essas reuniões institucionalizaram as relações interestatais, tornando-se momentos emblemáticos da regulamentação do acesso aos recursos naturais. Ribeiro (2010) afirma que as convenções internacionais representam uma possibilidade de conciliar interesses diversos de maneira negociada, permitindo que países com menos condições econômica e militar expressem suas posições, mesmo considerando a prescrição de relações desiguais entre os países parte. O Quadro 1 sintetiza alguns efeitos desses eventos sobre os países em desenvolvimento.

\section{Quadro 1}

Efeitos dos principais eventos internacionais sobre os países em desenvolvimento

\begin{tabular}{|c|c|}
\hline EVENTOS & EFEITOS \\
\hline Estocolmo (1972) & $\begin{array}{c}\text { Os países em desenvolvimento não aceitaram a estagnação econômica requerida } \\
\text { pelos limites do crescimento e passaram a receber investimentos por meio da } \\
\text { instalação de indústrias, que criaram passivos ambientais em seus territórios. }\end{array}$ \\
\hline Rio de Janeiro (1992) & $\begin{array}{c}\text { Foi estabelecido o princípio da responsabilidade comum, porém diferenciada, que } \\
\text { guiou os debates sobre mudança climática, nos quais os países que mais emitiram } \\
\text { gases do efeito estufa no passado resistiram, e resistem até o momento, em } \\
\text { financiar os estragos nos países mais pobres. A Convenção sobre Diversidade } \\
\text { Biológica estabeleceu que a tecnologia e produtos desenvolvidos por países } \\
\text { desenvolvidos com base em informação genética e conhecimento tradicional de } \\
\text { populações que vivem em países pobres devem ser repassados a estes. }\end{array}$ \\
\hline
\end{tabular}




\begin{tabular}{|c|c|}
\hline Joanesburgo (2002) & $\begin{array}{r}\text { O princípio da responsabilidade comum, porém diferenciada foi reafirmado, } \\
\text { mantendo para os países ricos que mais degradaram o ambiente uma } \\
\text { responsabilidade maior de renovação ambiental que os países de renda média e } \\
\text { baixa. Também foram estabelecidas metas para pautar as ações dos países } \\
\text { pobres no sistema internacional e estimular a cooperação interestatal. }\end{array}$ \\
\hline
\end{tabular}

Fonte: Adaptado de Ribeiro (2010).

O relatório das Nações Unidas que é objeto deste estudo tem como tema central o desenvolvimento sustentável. Contudo, assume-se o pressuposto de que a ONU não é ideologicamente neutra em suas posições no que se refere aos países desenvolvidos e em desenvolvimento. Acredita-se que as diretrizes estabelecidas pela ONU em seus documentos favorecem um grupo de países e desfavorece outro. Para discutir o papel dos países em desenvolvimento refletidos no relatório das Nações Unidas, se procederá a uma análise crítica do discurso. A próxima seção detalha o percurso metodológico adotado.

\section{Análise Crítica do Discurso como Recurso Metodológico}

Este é um estudo crítico, visto que busca revelar a relação de dominação entre a ONU e os países em desenvolvimento no que tange à construção da dimensão institucional do desenvolvimento sustentável. No nível organizacional, a teoria crítica busca reconhecer a repressão imposta pelas instituições dominantes e criar locais de trabalho livres de qualquer tipo de dominação, defendendo que as organizações atuem no sentido das necessidades humanas, conduzindo o desenvolvimento progressivo da sociedade como um todo e não apenas de uma elite (SOUZA, SALDANHA e ICHIKAWA, 2004). Na teoria administrativa e nas práticas organizacionais, a abordagem crítica pode contribuir com um posicionamento de atenção, reflexão e questionamento sobre o que é tradicional e habitual (DAVEL e ALCADIPANI, 2003). Todos estes aspectos de um estudo crítico no nível organizacional são aplicáveis neste estudo, em que se considera a ONU como um ator de destaque no cenário internacional e os países em desenvolvimento e atualmente desenvolvidos como formas organizacionais que são refletidas nas suas estruturas de governo.

Dado o amplo alcance do discurso da ONU, apesar do limitado poder efetivo de ação, esta parece desfrutar de um poder simbólico quando considerada a força de seu discurso (VAN DIJK, 2010). Assim, desconstruir para compreender os significados implícitos no discurso desta organização pode oferecer importantes informações acerca de suas ideologias.

Frente à proposta deste trabalho, a Análise Crítica do Discurso (ACD) aparece como uma importante alternativa metodológica uma vez que seu interesse está voltado especialmente para a relação entre linguagem e poder (FAIRCLOUGH, 2001; 2003; WODAK, 2004). A ACD é uma abordagem da Teoria Social do Discurso, desenvolvida por Norman Fairclough, que se fundamenta no pressuposto de que a linguagem é parte irredutível da vida social interconectada dialeticamente a outros elementos sociais (FAIRCLOUGH, 2003). A utilização dessa abordagem da ACD no estudo das organizações pode ser vista nos trabalhos de Misoczky e Ferreira (2005) e Costa, Barros e Martins (2012). Nessa proposta, o termo "discurso" indica uma visão particular da linguagem em uso, ou seja, o discurso é uma prática social que, articulada na linguagem, representa e significa o mundo, constituindo-o e construindo-o em significados (FAIRCLOUGH, 2001). Para o autor o discurso opera simultaneamente de três maneiras: ação, representação e identificação, ou seja, por meio da linguagem agimos (ação); expressamos nossa visão de mundo (representação); e nos posicionamos enquanto indivíduos (identificação). Portanto, o discurso representa os significados por trás do texto, o que implica que todo discurso é investido de ideologias e reflexo, também, de certa hegemonia (MEURER, 2005). Para Caldas Coulthard (2008, p. 31), "[...] sempre que interagimos, assumimos um ponto de vista ou perspectiva especial sobre o que quer que queiramos comunicar. Esta perspectiva sinaliza nossa visão de mundo e consequentemente nossas ideologias". 
Cabe destacar que, apesar do interesse particular da ACD pela função social exercida pela linguagem, os aspectos formais da língua guardam sua importância. É um processo central na análise crítica do discurso relacionar textos e prática social (CALDAS COULTHARD, 2008), já que se parte do pressuposto de que os textos contêm traços e pistas das rotinas sociais (MEURER, 2005). Conforme atesta Halliday (1998), uma análise de discurso sem evidências textuais é apenas um comentário sobre um texto ou um conjunto de convenções não linguísticas. Desta forma, na proposta teórico-metodológica de Fairclough (2001), a ACD se realiza em três dimensões: textual (vocabulário e gramática); discursiva (produção, distribuição e consumo) e social (ideologia e hegemonia). Conforme o autor, a prática textual guarda um poder de descrição; a prática discursiva, de interpretação; enquanto é na análise da prática social que está contido o domínio explicativo do fenômeno em análise. Assim, é nesta dimensão que se busca explicar as formas de ideologia e hegemonia contidas no discurso. Apesar da necessidade de analisar o evento discursivo de três ângulos (textual, discurso e social), o mesmo não se aplica aos significados realizados pela linguagem. Para fins de análise, é possível abordar o discurso em uma perspectiva de interesse específica para o estudo (acional, representacional ou identificacional). No Quadro 2, estão sintetizados os significados da linguagem e as principais categorias de análise relacionadas.

Quadro 2

Relação dos significados da linguagem e categorias de análise

\begin{tabular}{|c|c|}
\hline Significados da linguagem & Categorias analíticas \\
\hline Acional & Estrutura genérica e intertextualidade \\
\hline Representacional & Interdiscursividade e representações \\
\hline Identificacional & Modalidade e avaliação \\
\hline
\end{tabular}

Fonte: Adaptado de Fairclough (2003)

Neste trabalho, a análise crítica do discurso foi realizada na dimensão representacional, uma vez que o propósito central desta pesquisa foi o de revelar a representação da ONU no que tange ao papel dos países em desenvolvimento na dimensão institucional do desenvolvimento sustentável. Para desvendar os significados representacionais contidos no discurso, Fairclough (2003) indica que a análise do vocabulário fornece uma rica evidência, já que as escolhas lexicais para compor um texto são feitas de modo que uma ideia/representação específica de mundo possa ser transmitida. A análise linguística do sistema de transitividade também é um importante recurso para entender as representações, pois nos permite identificar nos textos os processos, os participantes e as circunstâncias. Desse modo, a transitividade sinaliza nas frases as associações entre o que é realizado (processos) e os papéis atribuídos aos envolvidos (participantes) (EGGINS, 1994). Por fim, as nominalizações também são sugeridas por Fairclough (2003) como uma importante categoria para análise da dimensão representacional.

\section{Definição e tratamento do corpus}

No final do ano 2010, o Departamento de Assuntos Econômicos e Sociais das Nações Unidas publicou o relatório "Objective and themes of the United Nations Conference on Sustainable Development" (UNITED NATIONS, 2010), que examina os temas da Conferência sobre Desenvolvimento Sustentável das Nações Unidas em 2012, a Rio+20. O relatório, constituído por 123 parágrafos divididos em quatros seções, reúne na seção III (Institutional framework for sustainable development) os principais pontos sobre o quadro institucional para o desenvolvimento sustentável. Para definir o corpus de análise, tomou-se como âncora as expressões que fizessem referência aos países em desenvolvimento ao longo do texto da seção III com o 
intuito de identificar os parágrafos mais importantes para o aprofundamento das análises. O Quadro 3, a seguir, retrata os parágrafos identificados. No documento original, cada parágrafo do relatório é sinalizado com um número sequencial. Este número foi mantido no texto retratado no Quadro 3 para facilitar possíveis consultas posteriores; também foram destacadas as expressões que representam os países em desenvolvimento.

\section{Quadro 3}

\section{Parágrafos que fazem referência aos países em desenvolvimento}

101. Ultimately the success or failure of sustainable development rests on implementation at the national and local levels. Such implementation could benefit from enhanced capacity-building efforts, particularly in the least developed countries, for analysis, establishment and enforcement of regulatory and incentive frameworks to shift towards sustainable consumption and production patterns.

104. Local governments are at the coalface of emerging challenges, such as the need to prioritize and strengthen the capacity to deliver basic services in the face of rapid, often unplanned urbanization in developing countries. In many developing countries, improved integration, coordination and resource-sharing between levels of government would improve access to basic services such as water, sanitation, health and housing. Also, engagement of civil society has proven to be a valuable means of implementation at the local level, especially but not only where the local authorities' capacities and resources are limited.

109. The strengthening of delivery channels of funding for sustainable development is critical for implementation. In that regard, the question of governance, in particular the relative influence over decisionmaking of donor and recipient countries, has been a key issue for debate. Currently the Global Environment Facility (GEF) serves as an operating entity of the financial mechanism for the United Nations Framework Convention on Climate Change, as well as the Convention on Biological Diversity, the Stockholm Convention and the United Nations Convention to Combat Desertification. Under its International Waters focal area, GEF finances activities to help countries collectively manage their transboundary surface water basins, ground water basins, and coastal and marine systems. GEF successfully leverages considerable co-financing, yet questions remain whether the available funds are adequate to cover the expanding needs of countries.

110. The international response to climate change has resulted in the creation of a number of funds, some under the aegis of the Framework Convention and Kyoto Protocol and others located in the World Bank. In that regard, the Adaptation Fund, which is mandated to finance concrete adaptation projects and programmes in developing countries that are parties to the Kyoto Protocol, marks a break with prevailing practice in that developing countries have a majority on the Adaptation Fund Board. Another novel feature of the Fund's operations is direct access, whereby the recipient country can access financial resources without going through an intermediary multilateral institution, as is the case for funding allocated under GEF. For its part, the World Bank in 2008 established the Climate Investment Funds, which include balanced representation from donor and beneficiary countries, but are not formally linked with the Framework Convention. Most recently, the Green Climate Fund, established at the sixteenth session of the Conference of the Parties to the Framework Convention, will be governed by a board of 24 members comprising equal representation from developed and developing countries.

113. The international financial institutions and the multilateral development banks are key institutional actors in relation to sustainable development. Recent reforms, which have increased the representation of developing countries, have enhanced the legitimacy of the governing bodies of the International Monetary Fund and the World Bank. The World Bank and the multilateral development banks have made considerable strides in incorporating sustainable development into their programmes and projects, for example, support for renewable energy and agriculture in the wake of the food crisis. Still, more effort is needed to continue such integration as well as to bridge the gap between those institutions and the rest of the United Nations system.

Fonte: Adaptado de United Nations (2010, grifo nosso). 
Assim, buscando revelar os significados representacionais contidos no discurso analisado, procurou-se identificar quem faz o que e em que circunstâncias por meio da análise linguística do sistema de transitividade, que é operacionalizada mediante três categorias básicas: processo, participante e circunstância. A seguir, nos Quadros 4 e 5, apresenta-se um exemplo de como este processo foi efetuado.

\section{Quadro 4}

\section{Exemplo 1 de análise da transitividade}

\begin{tabular}{|c|c|c|c|}
\hline Participante & Processo & Participante & Circunstância \\
\hline Such implementation & could benefit from & $\begin{array}{l}\text { enhanced capacity-building } \\
\text { efforts }\end{array}$ & $\begin{array}{l}\text { particularly in the least } \\
\text { developed countries }\end{array}$ \\
\hline
\end{tabular}

Fonte: Elaborado pelos autores.

Esse trecho pode ser lido da seguinte maneira: especificamente nos países em desenvolvimento avançados, esforços de capacitação podem beneficiar a implementação do desenvolvimento sustentável. Portanto, observe-se que há um pressuposto de que particularmente nos países em desenvolvimento a governança para o desenvolvimento sustentável precisa ser aprimorada. Por que particularmente nos países em desenvolvimento? Isto denota uma representação de desigualdade, atraso e incapacidade para o desenvolvimento sustentável em relação aos países desenvolvidos, aos quais essas recomendações não se aplicam.

\section{Quadro 5}

\section{Exemplo 2 de análise da transitividade}

\begin{tabular}{|c|c|c|c|}
\hline \multicolumn{2}{|c|}{$\begin{array}{c}\text { Trecho analisado: In many developing countries, improved integration, coordination and resource-sharing } \\
\text { between levels of government would improve access to basic services such as water, sanitation, } \\
\text { health and housing. }\end{array}$} \\
\hline Participante & Processo & Participante & Circunstância \\
\hline $\begin{array}{c}\text { improved integration, } \\
\text { coordination and } \\
\text { resource-sharing }\end{array}$ & would improve & $\begin{array}{c}\text { access to basic services } \\
\text { such as water, sanitation, } \\
\text { health and housing }\end{array}$ & $\begin{array}{c}\text { In many developing } \\
\text { countries }\end{array}$ \\
\hline
\end{tabular}

Fonte: Elaborado pelos autores.

Há uma série de significados representacionais implícitos no trecho exemplificado no Quadro 5, ou seja, o ponto de vista da ONU sobre os países em desenvolvimento. Nota-se que, de forma prescritiva, o discurso parte da prerrogativa de que nos países em desenvolvimento deve ser incrementado o "access to basic services such as water, sanitation, health and housing". Além disto, normatizam que a melhoria desses elementos pode ser obtida com "improved integration, coordination and resource-sharing". É por meio desta dinâmica de desconstrução e identificação de evidências textuais que crenças implícitas no discurso vêm à tona e permitem inferências da prática social.

Também a análise do vocabulário revela representações contidas no discurso. Como ilustração da dinâmica de análise adotada, observe-se o significado atribuído à expressão "desafios emergentes" no trecho a seguir: "Local governments are at the coalface of emerging challenges, such as the need to prioritize and strengthen 
the capacity to deliver basic services in the face of rapid, often unplanned urbanization in developing countries" (UNITED NATIONS, 2010, p. 24, grifo nosso). Neste parágrafo, "priorizar e fortalecer a capacidade de fornecer serviços básicos em face da urbanização rápida e não planejada" é hipônimo (um sentido estrito) de "desafios emergentes" no contexto dos países em desenvolvimento.

Em relação às nominalizações, recurso que consiste em generalizar processos, pode-se ocultar o agente e, portanto, a responsabilidade (FAIRCLOUGH, 2003), como no seguinte parágrafo:

Ultimately the success or failure of sustainable development rests on implementation at the national and local levels. Such implementation could benefit from enhanced capacitybuilding efforts, particularly in the least developed countries, for analysis, establishment and enforcement of regulatory and incentive frameworks to shift towards sustainable consumption and production patterns (UNITED NATIONS, 2010, p. 23, grifo nosso).

A palavra grifada é um exemplo de nominalização. Dessa maneira, a ação e o agente são subtraídos e o sentido de "avançados esforços de capacitação" é indefinido em nome da generalização de um processo.

Com base na dinâmica de análise exemplificada acima, procedeu-se à análise do corpus. Os principais achados são discutidos na seção a seguir.

\section{Análises e Discussões}

O relatório em análise foi produzido pela Organização das Nações Unidas, uma organização internacional que, em 1945, no período pós-Segunda Guerra Mundial foi formada por 50 países voluntariamente engajados em tratar da paz e do desenvolvimento mundial (TEIXEIRA, 1983). Atualmente há 193 países membros.

Dentro da ampla estrutura organizacional formada por conselhos, assembleias e secretarias, a unidade responsável pela produção do relatório tratado neste estudo foi o Departamento de Assuntos Econômicos e Sociais (DESA). A missão deste departamento é a de promover o desenvolvimento tendo por preocupação a equidade em países desenvolvidos ou em desenvolvimento. Entre as atribuições do DESA está a de fornecer suporte substancial para processos intergovernamentais sobre assuntos de desenvolvimento, incluindo-se a Conferência sobre Desenvolvimento Sustentável das Nações Unidas (Rio+20). Em uma resolução da Assembleia Geral das Nações Unidas, ficou decidido que a Conferência sobre Desenvolvimento Sustentável aconteceria em três encontros de comitês preparatórios.

O primeiro encontro aconteceu no mês de maio do ano 2010 em Nova Iorque, quando os objetivos da Conferência foram discutidos. Com base nas discussões do primeiro encontro, o relatório em análise neste estudo foi construído e, posteriormente, distribuído para os representantes dos diversos países no segundo encontro, que aconteceu no mês de março de 2011, também em Nova Iorque. Versões traduzidas em seis diferentes idiomas (árabe, chinês, inglês, francês, russo e espanhol) também foram distribuídas. A princípio, as traduções para seis idiomas parecem proporcionar coerência ao discurso já que o torna acessível à interpretação de um maior número de leitores. No entanto, ao ampliar a análise e considerar o contexto, evidencia-se a ausência da tradução justamente para o português, língua oficial do país sede do evento no qual o referido relatório será debatido. Com isso, uma expressiva parcela de cidadãos brasileiros deixa de ser receptor deste discurso e participante da discussão. Portanto, ainda que o relatório esteja disponível na página eletrônica da Conferência para a consulta do público geral, o seu consumo no Brasil se mantém, de certa forma, restrito. O terceiro encontro é a Conferência sobre Desenvolvimento Sustentável das Nações Unidas propriamente dita, em junho de 2012 no Rio de Janeiro.

O consumo do relatório aqui tratado realizou-se primeiramente de maneira coletiva, entre os representantes dos países presentes no segundo comitê preparatório, quando os temas abordados foram discutidos. Pelo fato de a Conferência sobre Desenvolvimento Sustentável das Nações Unidas ser um evento de interesse geral, o 
relatório também tem sido objeto de leitura de jornalistas para a elaboração de peças jornalísticas, de especialistas em sustentabilidade para avaliar as decisões no contexto macro, de empresários para avaliar as possíveis influências das sugestões do relatório nos processos produtivos, de professores para discutir os temas tratados em situações de ensino, e de ambientalistas representantes da sociedade civil para avaliar possíveis riscos das sugestões do relatório para o meio ambiente.

O texto do relatório tem a força de recomendar e sugerir ações, mas também de revelar informações que justificam as recomendações que são estabelecidas. Busca-se convencer o leitor a aceitar as recomendações determinadas no texto. Apesar de não serem previstas intenções de construção de algum instrumento normativo multilateral sobre os temas na Conferência, o texto do relatório é amplamente caracterizado por sentenças normativas. Assim, o relatório dá continuidade ao papel da ONU de apontar diretrizes que os países devem seguir para desenvolverem ações e políticas públicas. É importante destacar o seguinte trecho do próprio relatório que reforça essa afirmação: "The United Nations Development Group assumes a role in relation to development activities on the ground, operationalizing normative decisions through, for example, producing guidance notes for United Nations country teams" (UNITED NATIONS, 2010, p. 23). A questão que se faz pertinente é se essas diretrizes são favoráveis tanto para os países desenvolvidos quanto em desenvolvimento.

É importante destacar que o relatório foi produzido com base nos pontos discutidos coletivamente pelos participantes do primeiro comitê preparatório da Conferência. Portanto, trata-se de um texto que foi intrinsecamente construído com a utilização de outro texto manifestado alguns meses anteriormente à sua distribuição. Também se destacam algumas intertextualidades manifestas que refletem eventos passados tomados para a discussão sobre financiamento de programas. A Convenção-Quadro das Nações Unidas sobre a Mudança do Clima, a Convenção sobre Diversidade Biológica e a Convenção das Nações Unidas de Combate à Desertificação foram documentos adotados na Cúpula da Terra em 1992 (Rio 92); o Protocolo de Kyoto adotado em 1997 remete à redução de emissões de gases estufa e a Convenção de Estocolmo de 2001 remete à eliminação dos poluentes orgânicos persistentes. Entretanto, não foram todos os países membros das Nações Unidas que assinaram esses documentos, fato que revela conflitos entre os compromissos documentados e os programas desenvolvimentistas dos países que se recusaram a assiná-los.

$\mathrm{Na}$ análise da prática social, o relatório das Nações Unidas ressalta a importância do fortalecimento da coordenação e cooperação entre instituições e da avaliação dos acordos multilaterais de cooperação, como se demonstra no seguinte trecho:

It is important to define the rationale and purpose of multilateral environmental agreements' cooperation and set clear objectives and criteria to assess results. At the same time, initiatives for coordination must also be balanced against the need to respect the autonomy and legal mandates of the agreements. (UNITED NATIONS, 2010, p. 25).

- Este é um posicionamento das Nações Unidas que reflete a ideia de um mundo harmônico, onde os conflitos são vistos como anomalias que precisam ser erradicadas por meio de acordos multilaterais. Algumas escolhas lexicais evidenciam este posicionamento: agreements, set clear, coordination, respect.

- A preocupação com a avaliação destes acordos é bastante pertinente no momento atual, quando a tentativa de estabelecer acordos multilaterais tem sido frustrada. Entretanto, a questão que deve ser observada é que o relatório não faz nenhuma referência ao estabelecimento de acordos entre países em diferentes situações de desenvolvimento. Ao discutir a ordem ambiental internacional, Ribeiro (2010) afirma que parte dos países não aceita os termos finais dos acordos e não os assinam, ou o fazem indicando ressalvas ao texto, buscando a salvaguarda da soberania e protegendo seus interesses nacionais como aconteceu em 2009 na reunião em Copenhague.

Além disso, a análise do referido relatório evidencia duas questões centrais na percepção da ONU sobre o papel dos países em desenvolvimento na dimensão institucional do desenvolvimento sustentável: (1) a 
necessidade de criação de capacidades nacionais para a produção e o consumo sustentável e a (2) dinâmica do financiamento de fundos internacionais. Contudo, essas questões revelam implicações ideológicas que favorecem os países atualmente desenvolvidos e limitam o desenvolvimento dos demais países.

\section{(In)Capacidades nacionais para a produção e o consumo sustentável}

No vocabulário empregado no relatório das Nações Unidas para se referir aos países em desenvolvimento, encontram-se alguns termos diferentes: "países menos desenvolvidos", "países em desenvolvimento", "países recipientes" e "países beneficiários". O emprego dessas expressões antecipa algumas ideias sobre as quais o texto é construído. As expressões "países menos desenvolvidos" ou "países em desenvolvimento" ressaltam a ideia de uma estrutura global dicotômica, composta por países desenvolvidos de um lado e países não desenvolvidos de outro.

Os países em desenvolvimento também aparecem como lugar onde se realizam ações de: construção de capacidades para padrões de produção e consumo sustentável, priorização do fornecimento de serviços básicos, urbanização rápida e não planejada, coordenação insuficiente entre níveis de governo para garantir acesso a serviços básicos e recebimento de recursos financeiros para realização de projetos de adaptação à mudança climática. O primeiro momento em que os países em desenvolvimento são referenciados é quando se discute apenas uma das seis abordagens para o fortalecimento do quadro institucional, que é o objetivo de fortalecer as capacidades nacionais e locais para o desenvolvimento sustentável. Os países em desenvolvimento são referenciados novamente no encerramento da seção sobre as abordagens para o fortalecimento do quadro institucional, e se ressalta a importância dos governos locais para atender as necessidades básicas da população.

A sociedade civil é vista como uma parte do sistema social que complementa as atribuições do Estado especialmente quando este tem capacidades e recursos limitados, conforme retrata o seguinte trecho: "Also, engagement of civil society has proven to be a valuable means of implementation at the local level, especially but not only where the local authorities' capacities and resources are limited" (UNITED NATIONS, 2010, p. 25).

A noção de sociedade civil refletida no texto do relatório retoma a noção de sociedade civil na forma de organizações não governamentais, o que remete à ideia de cumprimento a demandas sociais não atendidas pelo aparelho estatal. Esta visão participa da matriz neoliberal na qual a sociedade civil é compreendida em um papel complementar ao do Estado e mercado e, portanto, considerada mais passiva e menos como uma esfera combativa (RAMOS, 2006).

As explicações da teoria da dependência (CARDOSO e FALETTO, 1975; CARDOSO, 1993) são bastante convincentes e é possível interpretá-las para além do poder e da dominação econômica. Durante todo o século XX, especialmente a partir da década de 1930, houve uma dominação cultural e simbólica dos países centrais para com os países dependentes da América Latina. Tal dominação se faz presente ainda na atualidade. Esse mesmo processo de dominação cultural parece ter ocorrido de maneira semelhante também nos países asiáticos a partir do final do século XX. Esse processo marca uma luta simbólica dentro da sociedade, não apenas nas questões culturais no sentido antropológico, mas também nas questões econômicas, provocando uma luta entre as empresas locais e as empresas estrangeiras. Esta discussão é útil à compreensão do papel dos países em desenvolvimento na criação de capacidades para a produção e o consumo sustentável.

Essas questões de dominação cultural precisam ser incluídas na discussão de dependência, apesar de ser justamente esse aspecto da sociedade que é amplamente defendido como a modernização da nação, uma vez que se supõe que o desenvolvimento ocorre nos países periféricos mesmo em situação de dependência. 
A distinção entre centro e periferia também é válida não somente para a economia, mas também para as manifestações culturais. A economia define os hábitos culturais de uma sociedade por um lado, mas a cultura tem o poder de legitimar a interferência econômica por outro. No primeiro caso, as tradições culturais dos países da América do Sul foram destruídas quase completamente pela dominação imperialista, especialmente as tradições indígenas. Atualmente, ao se constatar que nas poucas aldeias existentes é possível encontrar televisores e computadores entre outros produtos da cultura do centro, a teoria da dependência permite observar que as relações de hoje em dia são ainda uma forma de imperialismo. No segundo caso, as grandes redes de comida rápida dos países de centro precisam ter cardápios diferentes para países diferentes, pois facilmente as questões culturais não legitimariam a existência do cardápio praticado nos países de origem. A não comercialização de sanduíches com carne de boi na Índia é uma ilustração perfeita disso.

Em uma perspectiva do determinismo ambiental, Diamond (2005) destaca a importância das questões culturais quando se trata de padrões de produção e consumo na falta de marcos regulatórios e fiscais que obriguem a produção e o consumo sustentáveis. Essa discussão traz implicações na esfera do desenvolvimento. $\mathrm{O}$ relatório das Nações Unidas chama atenção para a criação de capacidades para a produção e o consumo sustentável especialmente nos países menos desenvolvidos ao mencionar que "[...] such implementation could benefit from enhanced capacity-building efforts, particularly in the least developed countries, for analysis, establishment and enforcement of regulatory and incentive frameworks to shift towards sustainable consumption and production patterns" (UNITED NATIONS, 2010, p. 23, grifo nosso). Entretanto, o impacto negativo do consumo nos países desenvolvidos é maior do que nos países não desenvolvidos, devido ao alto padrão consumista da população dos países desenvolvidos. Além disso, criar capacidade de produção sustentável é um caminho mais caro para as empresas dos países não desenvolvidos atualmente, o que torna o mercado inviável e consequentemente insustentável. Assim, a recomendação das Nações Unidas para criação de capacidade para produção sustentável parece ser pertinente, mas esconde riscos consideráveis aos quais os países em desenvolvimento são mais vulneráveis do que os países desenvolvidos.

De fato, o modelo dependente-associado de Cardoso (1993) é um modelo conformista e determinista da situação de atraso dos países periféricos, restando a estes apenas seguir as regras do centro para conseguir o máximo de desenvolvimento, que na verdade se representa como a sobra do desenvolvimento que acontece no centro. Já as ideias de Furtado (1994), apesar de exigirem um esforço maior do governo e da população nacional em direção ao desenvolvimento, parecem ser mais cuidadosas com as condições do bem-estar social em longo prazo, bem como com a possibilidade de romper a situação de dependência.

Com base nas ideias de Arrighi (1997), os países em desenvolvimento (semiperiférico) possuem a vantagem de ter acesso tanto aos países desenvolvidos (núcleo orgânico/centro) quanto aos menos desenvolvidos (periferia). Esta orientação bidirecional explica-se pelo fato de serem os países periféricos uma área de expansão para o mercado dos países em desenvolvimento, bem como estes também são uma área de expansão para o mercado dos países de centro. Isto parece ser vantajoso aos países em desenvolvimento já que proporciona uma melhor contextualização do cenário global e contribui em suas decisões políticas. Uma vantagem que pode ser atribuída especificamente aos países em desenvolvimento é o papel de mediador de conflitos entre os países de centro e periféricos. O acúmulo de experiência nas relações com ambos os lados do conflito pode proporcionar uma vantagem estrutural, ao legitimar os países em desenvolvimento como conhecedores dos conflitos de maneira mais ampla do que cada uma das outras partes. Desta forma, os países em desenvolvimento podem ser vistos como o terceiro que equilibra a exploração dos países de centro sobre os periféricos.

Contudo, é importante lembrar que os países desenvolvidos se encarregaram da criação de instituições internacionais ao longo do tempo, como a ONU, amarradas em acordos entre todos os demais países, que limitam a capacidade dos países em desenvolvimento de utilizar essas vantagens. Segundo Teixeira (1983), a ONU foi criada por iniciativa dos Estados Unidos com a intenção de definir regas consubstanciadas em acordos multilaterais no plano econômico (utilizando o pressuposto da paz e segurança). Estes acordos buscaram um ordenamento do mundo pós-guerra que favorecesse os interesses econômicos dos Estados Unidos pela formação de demanda para sua produção e pela reprodução do sistema capitalista. 


\section{Dinâmica de financiamento dos fundos internacionais}

A expressão "países recipientes" coloca os países não desenvolvidos como recebedores de ajuda, o que estabelece uma dinâmica na qual os países desenvolvidos são doadores ou provedores de algum recurso, enquanto os países não desenvolvidos são os recebedores ou depositários destes recursos. Esta ideia é complementada pelo uso da expressão "países beneficiários" observada no relatório, que coloca os países não desenvolvidos como beneficiados pelas doações de recursos dos países desenvolvidos. Assim, a noção de dependência e desenvolvimento dependente dos países em desenvolvimento aparece já na análise do vocabulário utilizado no relatório das Nações Unidas. Os países em desenvolvimento estão presentes como sujeitos do ato de acessar recursos financeiros e de participar de conselhos que controlam o financiamento de ações para o desenvolvimento sustentável.

A menção a países em desenvolvimento dá sentido também a discussões sobre a dinâmica de influências entre os países doadores e recebedores de financiamento na tomada de decisões, bem como em discussões sobre a representação desses países nos fundos de financiamento de desenvolvimento sustentável. Em seguida, há referências aos países em desenvolvimento na seção sobre a governança da dimensão ambiental da sustentabilidade, tratando da dinâmica de financiamento de ações para a sustentabilidade. A última referência aos países em desenvolvimento ocorre na seção sobre a governança das dimensões social e econômica da sustentabilidade, em uma discussão sobre a representação desses países nos órgãos internacionais de financiamento do desenvolvimento.

No relatório das Nações Unidas, os canais de distribuição de fundos financeiros são vistos como ponto crítico na implementação de ações, uma vez que os financiamentos causam influências nas decisões dos países doadores e recebedores. São apresentados casos em que a representação de países em desenvolvimento é reforçada nos conselhos dos fundos de financiamento como forma de tentar mostrar que as prioridades particulares dos países recebedores são respeitadas.

Para entender o papel dos países em desenvolvimento na dinâmica de financiamento dos fundos internacionais, é preciso discutir o desenvolvimento tardio destes países. De acordo com Chang (2002) e Fiori (1997; 1999), o significado atual do desenvolvimento para os países de capitalismo tardio apresenta-se em um complexo contexto que não permite a adoção de uma estratégia específica para este grupo de países. É certo que os países desenvolvidos criam as regras de um jogo que facilita o seu benefício próprio, colocando os países de desenvolvimento tardio em situação de desvantagem e, muitas vezes, sem alternativas. O jogo é o comércio internacional e as regras são as normas multilaterais que ditam as relações entre os países.

O caminho percorrido até o desenvolvimento pelos países atualmente desenvolvidos foi plenamente marcado por um momento de protecionismo cujo objetivo era criar internamente as condições favoráveis de competição no mercado internacional. Esse momento foi de importância ímpar para todos os países atualmente desenvolvidos em maior ou menor grau. É justamente esse momento que tem sido extorquido dos países de desenvolvimento tardio. Estes têm, então, de aceitar as regras de abertura para o comércio internacional puxado pelos países desenvolvidos, prejudicando a criação de condições favoráveis internamente, uma vez que os produtos dos países desenvolvidos demarcam território dentro dos países em desenvolvimento.

Aprofundando as ideias de Viola (1996), é possível entender que, apesar de o Brasil ter se direcionado para uma política globalista ao longo do tempo, esse movimento desperta desconfiança no movimento ambientalista nacionalista. Este debate envolve dois argumentos centrais: para os globalistas, as ideias ambientalistas são planetárias e não possuem fronteiras nacionais; para os nacionalistas, as ideias ambientalistas são carregadas de interesses estratégicos para as nações. Se por um lado existe uma pressão dos movimentos ambientalistas internacionais para a preservação ambiental de maneira particular nos países em desenvolvimento; por outro lado, existe uma desconfiança de que as reclamações destes movimentos são uma forma disfarçada de conter o desenvolvimento industrial e econômico dos países em desenvolvimento. 
Além disso, a legitimidade dos grupos ambientalistas com sede e apoiadores em países desenvolvidos pode ser contestada quando eles atuam nos países em desenvolvimento, uma vez que a possibilidade de ignorar fatores importantes do contexto local é maior do que quando ações ambientalistas são desenvolvidas por grupos nacionais.

Assim, o desenvolvimento dos países retardatários nesta dinâmica fica restrito a aceitar ou não as regras dos países desenvolvidos. Uma vez que as regras são aceitas, tenta-se buscar benefícios - mesmo que sejam mínimos e em proporção menor que os malefícios - da submissão aos países desenvolvidos. Na questão da distribuição de riqueza na sociedade, os malefícios são amplamente observáveis nos países de desenvolvimento tardio. A desigualdade social é a principal característica destes países, mesmo quando aceitam as regras dos países desenvolvidos em busca de aproveitar os nichos desenvolvimentistas do momento.

As contribuições de Stiglitz, Sen e Fitoussi (2009) e Bijl (2011) sobre a perspectiva da qualidade de vida como foco central do desenvolvimento sustentável podem dar sustentação ao enfrentamento dos problemas sociais nos países em desenvolvimento. Os países atualmente desenvolvidos não enfrentam a questão da desigualdade social como problema central durante sua trajetória de desenvolvimento, portanto, neste assunto, falta-lhes um conjunto de soluções que pudessem ser repassadas aos países de desenvolvimento tardio. Ao buscar meios de lidar com a desigualdade social, os países de desenvolvimento tardio colocam os indivíduos como ponto central nas estratégias de desenvolvimento. É a partir deste ponto que estes países podem buscar uma forma própria de desenvolvimento, distinta daquela dos países desenvolvidos.

O processo de globalização, que há mais de 20 anos difundiu-se e se estabeleceu entre os países, foi amplamente dirigido pelos países desenvolvidos e imposto aos países de desenvolvimento tardio. Ao ressaltar os aspectos de intercâmbio cultural e aproximação das fronteiras entre os países, a globalização mascarou o seu propósito central, o da internacionalização dos mercados financeiros, que se realizou em um contexto de competição extremamente desigual, e provocou um abismo desenvolvimentista entre os países desenvolvidos e os de desenvolvimento tardio.

A economia monetária é dirigida pelos países desenvolvidos, por meio das instituições que criaram e atualmente servem de modelo para os países de desenvolvimento tardio, que replicam a criação dessas instituições. Estas têm o papel de concentrar um conjunto de conhecimentos e práticas especializadas para lidar com o mercado monetário visando aos objetivos estratégicos definidos pelos Estados. Assim, é fácil perceber que os primeiros que se posicionaram na globalização com essa preocupação conseguem sair na frente, caso dos países centrais, especialmente os Estados Unidos, que assumem o papel hegemônico nesta questão.

De acordo com o relatório analisado, as Nações Unidas dedicam esforços para instituir uma dinâmica de financiamento do desenvolvimento sustentável, de maneira que os países em desenvolvimento sejam recebedores de recursos, enquanto os países desenvolvidos sejam doadores, posicionando-se de forma contrária a qualquer tipo de protecionismo econômico, como pode ser visto neste trecho: "An open multilateral trade regime has been an enabler for sustained economic growth and poverty eradication. Within the World Trade Organization, there is a need to continue promoting a better understanding of the links between trade and environment and between trade and social development" (UNITED NATIONS, 2010, p. 27).

Contudo, o recebimento de doações dos fundos de financiamento é um mecanismo que vicia as práticas de governo nos países em desenvolvimento, levando a que soluções internas não sejam praticadas. Desta forma, qualquer esforço para a criação de capacidades internas é restringido. Além disso, estes financiamentos podem ser tratados como o capital externo que financiou a industrialização da América Latina na década de 50, ou seja, como uma tentativa de estender a dominação dos países desenvolvidos, desta vez com relação ao que deve ser considerado sustentável ou não. O Quadro 6 resume os principais efeitos esperados nos países em desenvolvimento, considerando os dois temas analisados. A seguir, alguns comentários de considerações finais são apresentados. 
Quadro 6

Efeitos esperados da Rio+20 sobre os países em desenvolvimento

\begin{tabular}{|c|c|c|}
\hline TEMAS & \multicolumn{1}{|c|}{ EFEITOS } \\
\hline (In)Capacidades Nacionais para a & - $\begin{array}{l}\text { Reforço do alinhamento neoliberal, com o } \\
\text { reconhecimento da importância do Estado } \\
\text { passivo e das ações das ONGs no atendimento } \\
\text { das demandas públicas; }\end{array}$ \\
\hline Produção e o Consumo Sustentável & $\begin{array}{l}\text { Intensificação da dominação cultural dos países } \\
\text { desenvolvidos pelo estabelecimento dos padrões } \\
\text { de produção e consumo sustentáveis; }\end{array}$ \\
\hline - $\begin{array}{l}\text { Aumento dos custos de produção e perda de } \\
\text { competitividade das empresas e produtos }\end{array}$ \\
nacionais no mercado global.
\end{tabular}

Fonte: Elaborado pelos autores.

\section{Considerações Finais}

Partindo do pressuposto de que as instituições são elementos importantes no processo de desenvolvimento, este estudo buscou responder as seguintes perguntas: qual o papel dos países em desenvolvimento no relatório das Nações Unidas para a dimensão institucional do desenvolvimento sustentável? Quais as associações ideológicas possíveis com base no relatório? As Nações Unidas favorecem o desenvolvimento de países em desenvolvimento ou a manutenção da hegemonia dos países atualmente desenvolvidos?

É possível concluir que os países em desenvolvimento assumem pelo menos dois papéis claros na visão das Nações Unidas dentro do quadro institucional para o desenvolvimento sustentável: o papel de recebedor e beneficiário de investimentos de fundos internacionais para o desenvolvimento sustentável e o papel de produtor e consumidor insustentável.

O relatório analisado segue a orientação ideológica de cooperação internacional por meio de acordos multilaterais e livre mercado. Este tipo de orientação não é uma surpresa, visto que a ONU vem assumindo este posicionamento ao longo do tempo. Mas a questão que merece atenção é a implicação desse posicionamento no progresso dos países em desenvolvimento, conforme foi tratado neste estudo. 
Desta forma, as diretrizes que as Nações Unidas estabeleceram no relatório para a Rio+20 favorecem sobremaneira os países atualmente desenvolvidos. Os países em desenvolvimento podem ser favorecidos apenas com algum desenvolvimento do tipo dependente-associado, que tem limites claros e impõe situações menos privilegiadas aos países em desenvolvimento do que aos países atualmente desenvolvidos. Desta forma, o relatório das Nações Unidas para a Rio+20 não fortalece uma mudança discursiva ou alguma forma de transpor a situação dominante dos países atualmente desenvolvidos.

Com relação ao percurso metodológico tomado neste estudo, a análise crítica do discurso mostrou-se como um método de análise poderoso para revelar inclinações ideológicas. Destaca-se a importância do contexto na análise crítica do discurso, que é imprescindível para a revelação do que não está explicitamente dito no texto analisado, mas é reproduzido na prática discursiva e na prática social.

Como sugestões para futuras pesquisas, é importante que outras aplicações da análise crítica do discurso sejam realizadas em outras manifestações das Nações Unidas, bem como de diversas organizações internacionais para desmistificar a noção de neutralidade ideológica na posição dessas instituições. Para compreender a luta hegemônica no nível global, também um meio de obter respostas interessantes está em analisar discursos dos países em desenvolvimento para questões específicas elaboradas pelas Nações Unidas e outras instituições internacionais.

\section{Referências}

ALMEIDA, J. E. Subdesenvolvimento e dependência: uma análise comparada de Celso Furtado e Fernando Henrique Cardoso. 2009. Tese (Doutorado em Economia) - Universidade Federal do Rio Grande do Sul, Porto Alegre, 2009.

ALVES, A. R. C. O conceito de hegemonia: de Gramsci a Laclau e Mouffe. Lua Nova, n. 80, p. 71-96, 2010.

AREND, M.; CARIO, S. A. F. Desenvolvimento e desequilíbrio industrial no Rio Grande do Sul: uma análise secular evolucionária. Economia e Sociedade, v. 19, n. 2 (39), p. 381-420, ago., 2010.

ARRIGHI, G. A ilusão do desenvolvimento. Petrópolis, RJ: Vozes, 1997.

BIJL, R. Never waste a good crisis: towards social sustainable development. Social Indicators Research, v. 102, p. $157-168,2011$.

CALDAS COULTHARD, C. R. Da análise do discurso à análise crítica do discurso: introduzindo conceitos. In: CALDAS COULTHARD, C. R.; SCLIAR CABRAL, L. Desvendando discursos: conceitos básicos. Florianópolis: UFSC, 2008. p. 373.

CARDOSO DE MELLO, J. M. A contra-revolução liberal-conservadora e a tradição crítica latino-americana. In: TAVARES, M. C.; FIORI, J. L. Poder e dinheiro: uma economia política da globalização. Petrópolis, RJ: Vozes, 1997. p. 15-24.

CARDOSO, F. H. As idéias e seu lugar: ensaios sobre as teorias do desenvolvimento. Petrópolis: Vozes, 1993.

. ; FALETTO, E. Dependência e desenvolvimento na América Latina. 3a. ed. Rio de Janeiro: Zahar, 1975.

CHANG, H-J. Chutando a escada: a estratégia do desenvolvimento em perspectiva histórica. São Paulo: Unesp, 2002.

CONCEIÇÃO, O. A. C. Instituições, crescimento e mudança na ótica institucionalista. Porto Alegre: FEE. Teses FEE 1, 2002.

COSTA, A. M.; BARROS, D. F.; MARTINS, P. E. M. A alavanca que move o mundo: o discurso da mídia de negócios sobre o capitalismo empreendedor. Cad. EBAPE.BR, v. 10, n. 2, p. 357-375, 2012. 
DAVEL, E.; ALCADIPANI, R. Estudos críticos em administração: a produção científica brasileira nos anos 1990.

Revista de Administração de Empresas, v. 43, n. 4, p. 72-85, out./dez. 2003.

DIAMOND, J. Colapso. Rio de Janeiro: Record, 2005.

EGGINS, S. An introduction to Systemic Functional Linguistics. London: Pinter, 1994.

FAIRCLOUGH, N. Discurso e mudança social. Tradução de Izabel Magalhães. 1a. ed. Brasília: Universidade de Brasília, 2001. 320 p.

Analysing discourse: textual analysis for social research. London: Routledge, 2003.

FIORI, J. L. Globalização, hegemonia e império. In: TAVARES, M. C.; FIORI, J. L. Poder e dinheiro: uma economia política da globalização. 5a. ed. Petrópolis, RJ: Vozes, 1997.

Introdução: De volta à questão da riqueza de algumas nações. In: FIORI, J. L. (Org.). Estados e moedas no desenvolvimento das nações. 2a. ed. Petrópolis, RJ: Vozes, 1999.

FURTADO, C. Pequena introdução ao desenvolvimento: enfoque interdisciplinar. São Paulo: Nacional, 1980. A superação do subdesenvolvimento. Economia e Sociedade, n. 3, p. 37-42, dez., 1994.

GARCIA, A. S. Hegemonia e imperialismo: caracterizações da ordem mundial capitalista após a Segunda Guerra Mundial. Contexto Internacional, v. 32, n. 1, p.155-177, 2010.

HALLIDAY, M. T. K. An introduction to functional grammar. London: Arnold, 1998.

KATES, R. W.; PARRIS, T. M.; LEISEROWITZ, A. A. What is sustainable development? Goals, indicators, values, and practice. Environment: Science and Policy for Sustainable Development, v. 47, n. 3, p. 8-21, 2005.

KENNEDY, P. M. Preparando para o século XXI. Rio de Janeiro: Campus, 1993.

LEIS, H. R. A modernidade insustentável: as críticas do ambientalismo à sociedade contemporânea. Montevideo: Coscoroba, 2004.

MEURER, J. L. Gêneros textuais na análise crítica de Fairclough. In: MEURER, J. L.; BONINI, A.; MOTTA-ROTH, D. Gêneros: teorias, métodos, debates. São Paulo: Parábola, 2005. p. 295.

MISOCZKY, M. C.; FERREIRA, C. S. A construção simbólica da definição de governar e de governador realizada pelo jornal Zero Hora nas três últimas eleições gaúchas. Cad. EBAPE.BR, v. 3, n. 4, p. 1-17, 2005.

ORGANIZAÇÃO PARA A COOPERAÇÃO E DESENVOLVIMENTO ECONÔMICO. Measuring and fostering well-being and progress: The OECD Roadmap. Busan: OECD, 2009.

RAMOS, L. C. S. Civil society in an age of globalization: a neo-Gramscian perspective. Journal of Civil Society, v. 2 , p. $143-163,2006$.

RIBEIRO, W. C. Geografia política e gestão internacional de recursos naturais. Estudos Avançados, v. 24, n. 68, 2010.

SEN, A. Desenvolvimento como liberdade. São Paulo: Companhia das Letras, 2000.

SOUZA, N. J. Desenvolvimento econômico. 4a. ed. São Paulo: Atlas, 1999.

SOUZA, P. R. B.; SALDANHA, A. N. K.; ICHIKAWA, E. Y. Teoria Crítica na Administração. Caderno de Pesquisas em Administração, v. 11, n. 3, 2004.

STIGLITZ, J.; SEN, A.; FITOUSSI, J.P. Report of the measurement of economic performance and social progress. Paris, 14 Sept., 2009. 
TEIXEIRA, A. O movimento da industrialização nas economias capitalistas centrais no pós-guerra. 1983. Dissertação (Mestrado em Economia) - Programa de Pós-graduação em Economia, Universidade Federal do Rio de Janeiro, 1983.

UNITED NATIONS. Report of the world commission on environment and development: our common future. United Nations, 1987.

Objective and themes of the United Nations Conference on Sustainable Development. Report of the Secretary-General. 2010.

http://www.uncsd2012.org/rio20/index.php?page=view\&type=400\&nr=10\&menu=45>. Acesso em: 30 jan. 2012.

VAN BELLEN, H. M. Indicadores de sustentabilidade: uma análise comparativa. 2a. ed. Rio de Janeiro: FGV, 2006.

. As dimensões do desenvolvimento: um estudo exploratório sob as perspectivas das ferramentas de avaliação.

Revista Ciência da Administração, v. 12, n. 27, 2010.

VAN DIJK, T. Discurso e poder. 2. ed. São Paulo: Contexto, 2010.

VEIGA, J. E. A emergência socioambiental. São Paulo: Senac, 2007.

VIOLA, E. A multidimensionalidade da globalização, as novas forças sociais transnacionais e seu impacto na política ambiental do Brasil, 1989-1995. In: COSTA, L.; VIOLA, E. (Org.). Incertezas de sustentabilidade na globalização. Campinas: UNICAMP, 1996.

WODAK, R. Critical Discourse Analysis. In: SEALE, C. et al. (Ed.). Qualitative Research Practice. Sage: London, 2004. p. 197-213.[c1] 